\title{
Endovascular treatment of traumatic carotid cavernous fistula with trapping technique
}

\author{
Benny Young, Ahmad Faizal M. Ali
}

Department of Radiology, School of Medicine, University Malaysia Sarawak (UNIMAS), Hospital Umum Sarawak, Kuching, Malaysia

\begin{abstract}
Abstrak
Penatalaksanaan fistula arteri karotis kavernosa secara endovaskular konvensional melibatkan penempatan material secara langsung, baik itu koil, balon atau keduanya. Tujuan akhir adalah tertutupnya fistula dan terjaganya arteri karotis. Tetapi dalam beberapa kasus dengan laserasi arteri karotis yang parah, tatalaksana endovaskular yang memungkinkan adalah dengan menutup pengisian fistula dari sirkulasi otak. Metode ini dikenal dengan nama 'trapping technique' yang melibatkan metode penutupan arteri karotis, dikerjakan pada kasus ini dengan hasil yang baik. (Med J Indones. 2013;22:178-82. doi: 10.13181/mji.v22i3.588)
\end{abstract}

\begin{abstract}
Conventional endovascular treatment for carotid cavernous fistula (CCF) involves a direct delivery of either coils, detachable balloon or both to the fistula with end point of CCF resolution and carotid artery preservation. But in few cases with severe laceration of carotid artery, the feasible endovascular technique applicable is by blocking the filling of fistula from cerebral circulation. This method known as trapping technique which implicates carotid artery occlusion, was performed in our present case with good result. (Med J Indones. 2013;22:178-82. doi: 10.13181/mji.v22i3.588)
\end{abstract}

Keywords: Carotid cavernous fistula (CCF), carotid occlusion, trapping technique

Trauma is known as the most common cause of direct carotid cavernous fistula (CCF). A carotid artery injured by bony fragment has a through communication to the cavernous sinus with inherent fast flow via the fistula. It was grouped as type A in Barrow classification; commonly and simply known as CCF. It is a progressive medical problem where spontaneous resolution rarely occur. If left untreated, CCF can lead the patient to devastating conditions. Arterialization of the cavernous and cerebral venous flow may cause loss of eye vision, cerebral infarction or hemorrhage associated with venous hypertension, and sinus or venous aneurysm. ${ }^{1,2}$

Endovascular treatment for CCF has widely replaced surgical treatment. Direct delivered coils or balloons to the fistula either using trans-arterial or transvenous approach has become the standard conventional endovascular treatment. An ideal goal of endovascular treatment is achieving preservation of the main carotid artery with complete occlusion of the CCF. ${ }^{3}$ The success of these methods relies on a clear delineation of the fistula's track and the accessibility of the intended vessels. Several maneuvers such as Mehringer-Hieshima maneuver [gentle ipsilateral internal carotid (IC) injection during manual compression of the ipsilateral carotid artery] and Heuber maneuver (ipsilateral carotid compression during vertebral artery injection) are theoretically useful to aid outlining on the site of carotid's tear. ${ }^{4}$

The other factor that influences success of endovascular treatment is the size of carotid tear. Oversize tear associates with a risk of coils or balloon migration to the carotid artery. Subsequently, a large tear is accounted for total diversion flow into cavernous sinus with ensuing poor outline of the long course of cerebral carotid artery. Hence, this circumstance precludes interventionists from placing a non-detachable balloon as a safety mean to avoid coil or balloon migration during their deployment. Due to these aforementioned difficulties, a trapping technique is considered as an alternative endovascular method for CCF with large tear. The principal of trapping technique is obliteration of fistula's filling from the carotid artery and retrograde intracranial perfusion. ${ }^{5,6} \mathrm{We}$ report one case of CCF with inherent difficulty that warranted endovascular trapping technique with description on the technical consideration and suggestions to achieve success ful treatment.

\section{CASE REPORTS}

A 46-year old male was admitted to our hospital for a close head injury following a high speed motor collision. He suffered from multiple facial and skull base fractures. Two days after, we noted that he had a loss of right eye's vision, proptosis and chemosis with decreased level of consciousness. A post traumatic direct $\mathrm{CCF}$ was suspected and a diagnostic angiogram was performed.

\section{Technique}

Diagnostic angiogram was performed for pre-treatment evaluation by puncturing right femoral artery. A 4 


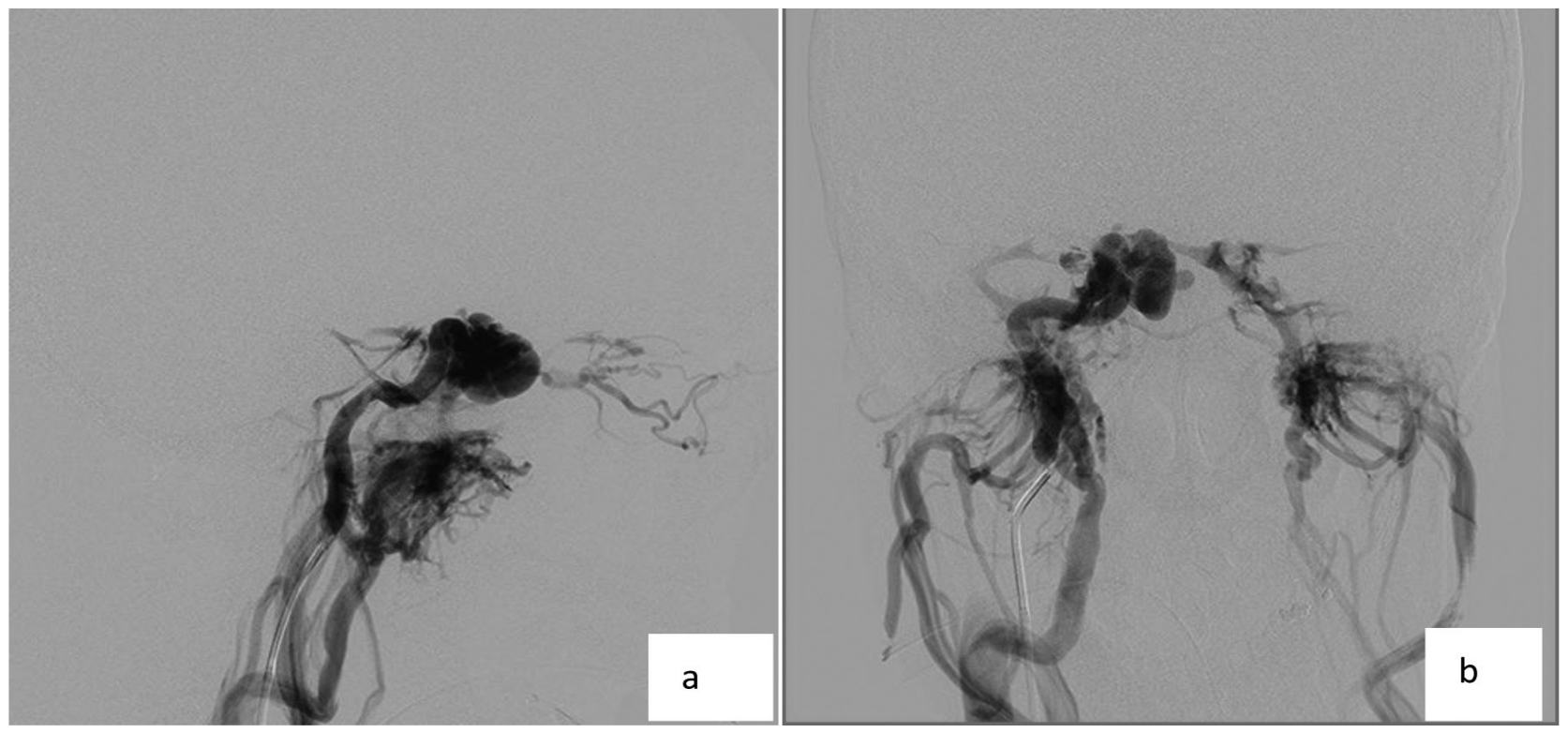

Figure 1. A) Pre-treatment diagnostic angiogram via right carotid artery from lateral view, B) AP view demonstrated a direct right $C C F$ with torrential flow to cavernous sinus and nearly absent of distal intracranial flow. The subsequent venous drainage to the superior ophthalmic vein, retroclival plexus, and pterygo-palatine plexus were seen

F vertebral angiogram catheter was used for cerebral arteriogram. Right internal carotid artery (ICA) arteriogram showed direct type of right CCF secondary to severe laceration of carotid artery. CCF demonstrated a total diversion flow to cavernous sinus and its tributaries with almost absence of right intracranial carotid flow. The right ophthalmic artery was totally not opacified nor received any collateral; which accounted for the loss of patient's right eye vision. The involved and opacified venous drainage were the right ophthalmic vein, bilateral pterygopalatine plexus, retroclival plexus, and the contralateral cavernous sinus (Figure. 1). The right vertebral arteriogram demonstrated a retrograde filling of the CCF through the right posterior communicating artery (PCOM) (Figure 2).

We estimated that it was not possible to navigate the microcatheter across the cavernous segment of carotid artery and advance it into the fistula due to the fact that a delineation of long segment carotid artery was not present. The non-opacified inferior petrous sinus or a good size of ophthalmic vein had deterred us from the option of transvenous approach.

Therefore, we chose a method to close the fistula by trapping its flow but with a consequence of occluding the carotid artery. This procedure comprised a closing of the proximal carotid artery with a detachable balloon and blocking the retrograde flow of the fistula from any of the collateral in the circle of Willis. The latter was achieved by occluding the pre-clinoid cavernous part of carotid via right PCOM.

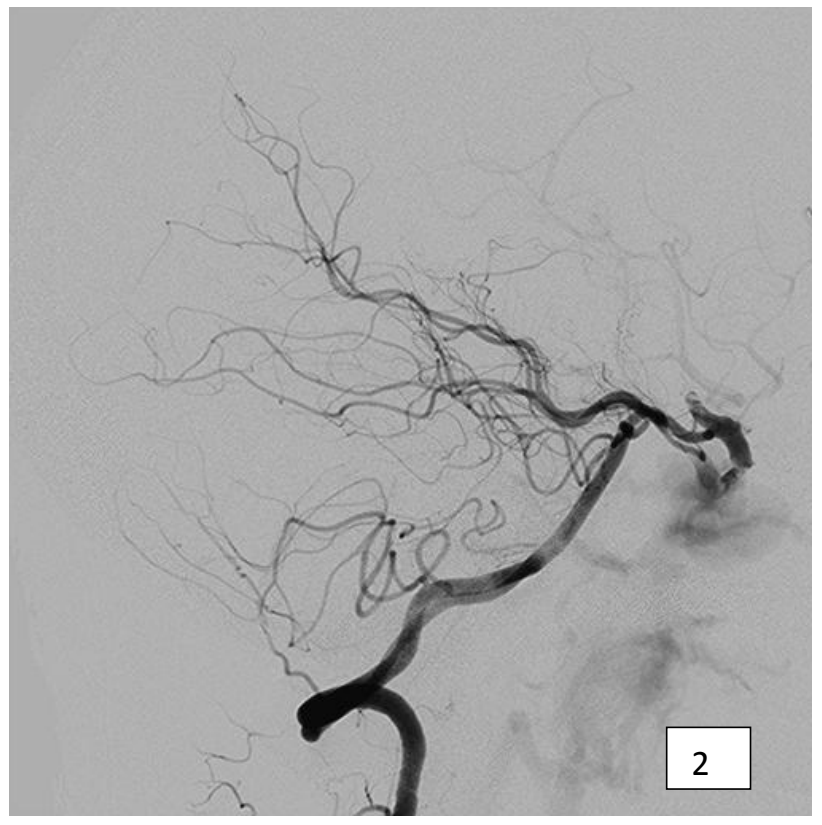

Figure 2. Lateral view of right vertebra arteriogram showed right $C C F$ recruited a retrograde perfusion through the right posterior communicating artery. It demonstrated clearly that the distal and proximal portion of the cavernous segment of right carotid artery was not communicating, consistent with severe laceration

Prior to the occlusion procedure, the patient was heparinized by giving a bolus of intravenous 3,000 units of heparin. A $6 \mathrm{~F}$ Fagomax introducer catheter was advanced carefully into the proximal right ICA. A 0.019-in over the wire Excelcisor SL 10 microcatheter 
(Boston Scientific, Fremont, CA) with a 0.014-in hydrophilic guidewire (Synchro 14; Boston Scientific) were run across coaxial within the guider. A continuous flushing system using a pressurized bag filled with 1,000 units of heparin in $1 \mathrm{~L}$ of normal saline was connected to the introducer catheter via the Tuohy-Borst adaptor. The first step of our treatment was to microcatheterize the right PCOM from the right vertebral artery. Following it, we advanced our microcatheter into the short part of the pre-clinoid part of the carotid artery and deploying two soft platinum GDC coils, size $4 \mathrm{~mm} \times 12 \mathrm{~cm}$ and $5 \mathrm{~mm}$ x $20 \mathrm{~cm}$ (Helix Axium ev3, Irvine CA) each. A control run post coiling revealed a persistent small opening to the fistula at the posterior aspect (Figure 3). In order to have a complete closing of this retrograde filling, a $3 \mathrm{mls}$ of $50 \%$ mixed Histoacryl liquid glue: Lipiodol solution (Lipiodol; Guerbet, Genova, Italy; Histoacryl, B Braun, Melsungen, Germany) was delivered into the pre-existing coils pack. Post embolization with combination of coils and adhesive histoacryl liquid showed a complete closing of the retrograde perfusion to the fistula with preservation of the PCOM (Figure 4).

The next step was to occlude the carotid artery just proximal to the site of fistula by using a detachable balloon. A number 9 latex gold valve balloon (Nycomed, France) was prepared and mounted on 2.7 F MABDE microcatheter. Through the 6 F Fagomax introducer catheter, the balloon was floated past the cervical ICA and navigated into the proximal cavernous segment of carotid artery. After the balloon was correctly placed into this area, it was fully inflated with $1 \mathrm{~mL}$ of Visipague (GE Health Care, US) contrast media and detached. A control run via the introducer catheter showed a complete occlusion of the proximal carotid artery. A left carotid angiogram showed the right intracranial perfusion was well maintained via the collateral perfusion at circle of Willis (Figure 5).

One day after endovascular treatment, the patient showed improvement of his right eye's proptosis and chemosis even though his right eye's vision was not able to be salvaged. Follow up after 3 months showed that the patient remained free from right CCF symptoms with absence of any cerebral ischemic due to carotid occlusion.

\section{DISCUSSION}

Direct CCF is considered as a progressive neurosurgical case which needs an early diagnostic ruling with prompt management. The indications for urgent treatment of CCF include the following :1) progressive visual loss, 2) epitaxis, 3) sphenoid sinus aneurysm, 4) comatose patients in whom intracranial lesions have been excluded, 5) re-routing of the venous drainage

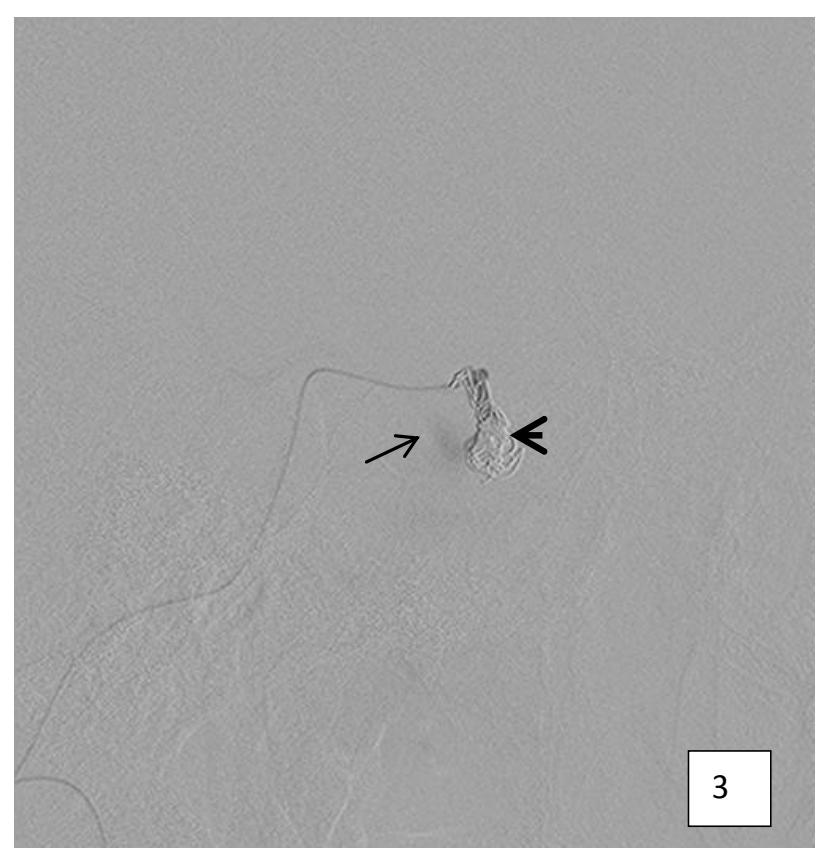

Figure 3. Post delivery of 2 GDC microcoils (arrow head) to the pre-clinoid carotid artery. Angiogram via microcatheter in the PCOM showed minimal filling to the fistula at the posterior aspect (arrow)

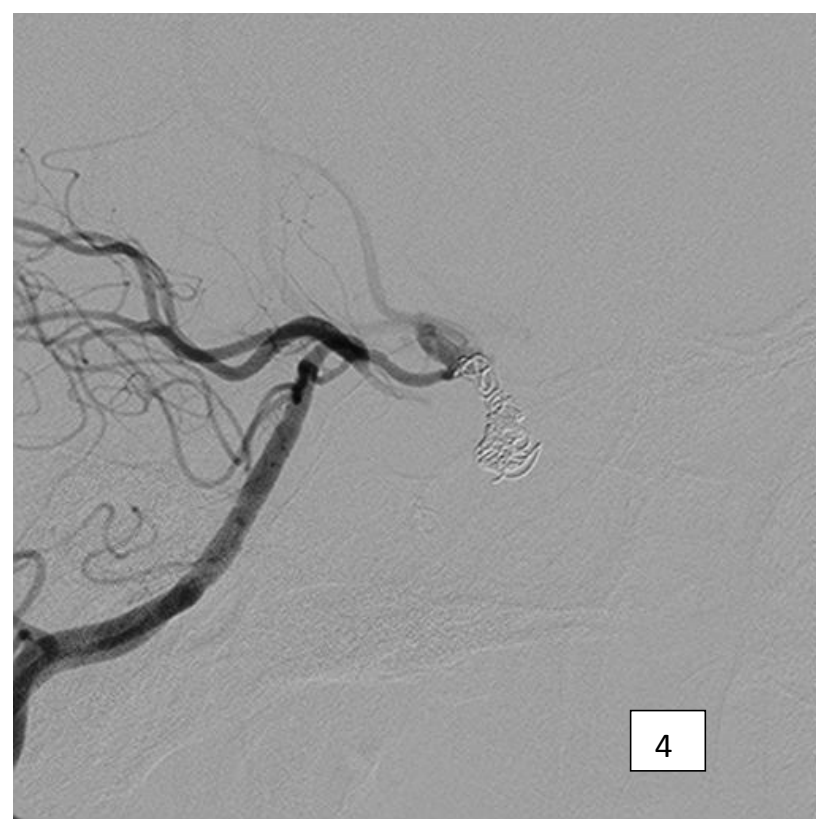

Figure 4. The short portion of pre-clinoid carotid artery was totally occluded after delivery of 50\% histoacryl glue into the pre-existing packed GDC coils. A subsequent closing of the anterograde filling of the fistula was performed by proximal carotid occlusion with detachable balloon

due to balloon migration anteriorly or posteriorly, in which rapid aggravation of ophthalmic symptoms or intradural complication such as bleeding can occur. ${ }^{5-7}$ 


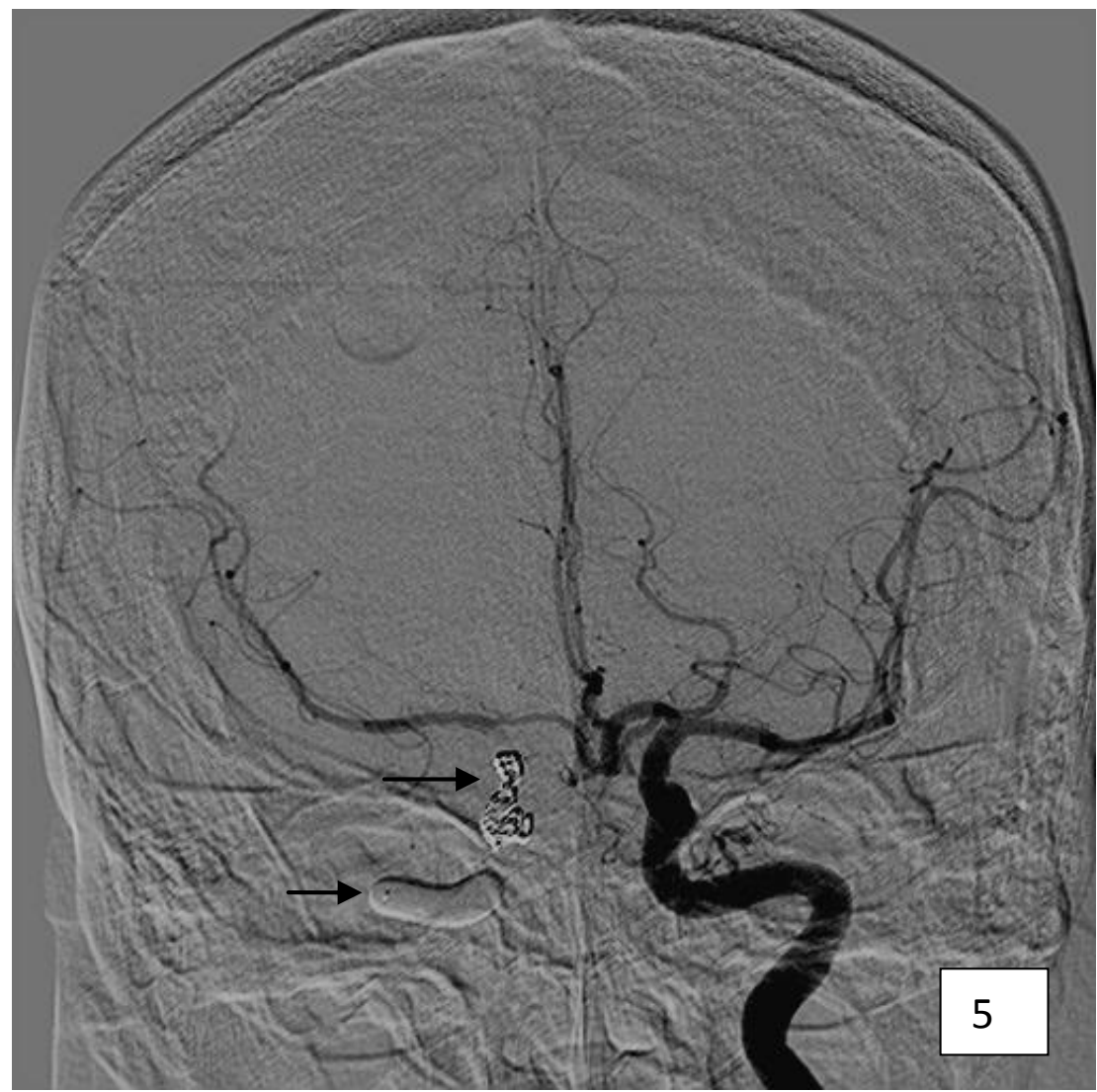

Figure 5. Final angiogram via left carotid artery post posterior coiling and glue (arrow) and balloon occlusion at the proximal right carotid artery (arrow head) showed trapping of right fistula's flow. The right intracranial flow was maintained via collateral from the left carotid circulation

Most of the reported success rate of conventional endovascular treatment of direct CCF using detachable balloon or platinum coils are about $75 \%-88 \%$ with preservation of the main carotid artery. ${ }^{4-6}$ For the rest of the cases, the occlusion of the main carotid artery is contrived to treat the fistula. Cases which are treated by occlusion of the main artery inherently have large tear in which the flow of carotid artery is profoundly terminated in the cavernous sinus.

The occlusion of carotid artery as treatment of choice has a relevance in our present case. The technical difficulties conceived from the lacerated artery were addressed. The associated massive flow due to large tear into fistula and cavernous sinus created a poor delineation of the fistula's orifice and its track. Hence, the consequence was a blind track, making it difficult to navigate any microcatheter system to the fistula and deploying the embolized materials. Furthermore, the placement of any coils or detachable balloons within the fistula carried a high risk of migration to the carotid artery from the large artery rent to the fistula. In addition, the predominant redirection of the CCF to pterygoid plexus had also precluded our option to approach the fistula via inferior petrous or inferior ophthalmic veins for transvenous delivered coil embolization.

A case series of trapping technique for CCF consisted of 4 patients was reported by Coley et al. In three cases, a retrograde flow trapping of CCF was performed via anterior communicating artery access with one case required PCOM for the access. In all these cases, closing of the distal cavernous carotid artery was successfully achieved by packing of platinum coils. Similar with our reported case, the occlusion of the proximal carotid artery in this case series was performed using a detachable balloon. ${ }^{8}$

An alternative method for treating severe direct CCF is placing a stent dedicated for intracranial carotid artery. A case series of covered stent or bare metal stent utilization in concomitant with coil placement showed a good technical success. The physical features of stent comprising the size, flexibility, conformity and compliance with vascular tortuosity are determinant factors to achieve a good result. However, the long-term patency of the stent has not been well established. ${ }^{9,10}$ 
Carotid artery occlusion method is not a risk free procedure. Brain ischemic is a known early complication of post carotid occlusion which is secondary to abrupt changes of the brain auto-regulation. A prior balloon test occlusion (BTO) for assessing the availability of collateral circulation while judging the patient's tolerance to carotid occlusion treatment by assessing patient's neurocognitive during BTO should be done to reduce the risk of post occlusion brain ischemic. However, some patient with critical clinical condition can be exempted from BTO. ${ }^{11-}$ ${ }^{13}$ Hypotension is known as a predisposing factor for this cerebrovascular event post carotid occlusion. A close monitoring with comprehensive intensive care is mandatory to minimize this pertaining complication after carotid occlusion procedure.

In conclusion, trapping technique with endovascular approach is feasible for treating a high flow carotid cavernous fistula in severely injured carotid artery. In the availability of stent designed for intracranial use and a good experience from the operators, a method of stent placement for carotid reconstruction and excluding fistula's flow can be considered. Hypotension is a known predisposing factor for brain ischemic complication post carotid occlusion, for which preventive measurement must be carried out accordingly.

\section{Acknowledgments}

The author thanks Dr. Lau Jia Him of Radiology Department, General Hospital Kuala Lumpur for his contribution on technical assistance in performing the endovascular procedure.

\section{REFERENCE}

1. Krings T, Geibprasert S, Brugge KG. Case Based Interventional Neuroradiology. New York: Thieme; 2011.
2. Halbach VV, Higashida RT, Hieshima GB, et al. Interventional neuroradiology. AJR Am J Roentgenol. 1989;153(3):467-76.

3. Sarbienko FA. Balloon catheterization and occlusion of major cerebral vessels. J. Neurosurg. 1974;41(2):125-45.

4. Halbach VV, Hieshima GB, Higashida RT, Reicher M. Carotid cavernous fistulae: indications for urgent treatment. AJR Am J Roentgenol. 1987;149(3):587-93.

5. Morris PP. Balloon reconstructive technique for the treatment of a carotid cavernous fistula. AJNR Am J Neuroradiol. 1999;20(6):1107-9.

6. Moris PP. Carotid Cavernous Fistulas. In: Moriss PP, editors. Interventional and Endovascular Therapy of the Nervous System: A Practical Guide. New York: SpringerVerlag; 2002. p. 177-90.

7. Cho JH, Jung Cy, Sheen SH, Kwon BJ, Han MH. Traumatic carotid cavernous fistula caused by intradural aneurysm rupture: A case report. Neurointervention. 2006;1:39-43.

8. Coley SC, Pandya H, Hodgson TJ, Jeffree MA, Deasy NP. Endovascular trapping of traumatic carotid cavernous fistulae. AJNR Am J Neuroradiol. 2003;24:1785-8.

9. Gomez F, Escobar W, Gomez AM, Gomez JF, Anaya CA. Treatment of carotid cavernous fistulas using covered stents: midterm results in seven patients. AJNR Am J Neuroradiol. 2007;28(9):1762-8.

10. Morón FE, Klucznik RP, Mawad ME, Strother CM. Endovascular treatment of high-flow carotid cavernous fistulas by stent-assisted coil placement. AJNR Am J Neuroradiol. 2005;26(6):1399-404.

11. Mathis JM, Barr JD, Jungreis CA, et al. Temporary balloon test occlusion of the internal iarotid artery: Experience in 500 cases. AJNR Am J Neuroradiol. 1995;16(4):749-54.

12. Morris P. Balloon test occlusion and post-occlusion patient care. In: Morris P, editors. Interventional and Endovascular Therapy of the Nervous System: A Practical Guide. New York: Springer-Verlag; 2002. p. 193-201.

13. Wan WS, Lai V, Lau HY, Wong YC, Poon WL, Tan CB. Endovascular treatment paradigm of carotid blowout syndrome: review of 8-years experience. European Journal of Radiology. 2013;82(1):95-9. 